ECCOMAS

Proceedia
COMPDYN 2021

$8^{\text {th }}$ ECCOMAS Thematic Conference on Computational Methods in Structural Dynamics and Earthquake Engineering M. Papadrakakis, M. Fragiadakis (eds.) Streamed from Athens, Greece, 28 - 30 June 2021

\title{
SOIL-STRUCTURE INTERACTION IN THE SEISMIC VULNERABILITY ANALYSIS OF RC BUILDINGS. APPLICATION TO A CASE STUDY BUILDING LOCATED IN SOUTHWESTERN SPAIN
}

\author{
M.V. Requena-Garcia-Cruz ${ }^{1}$, A. Morales-Esteban ${ }^{1}$, P. Durand-Neyra ${ }^{1}$, E. Romero- \\ Sánchez ${ }^{1}$ \\ ${ }^{1}$ Department of Building Structures and Geotechnical Engineering, University of Seville, Spain. Av. \\ Reina Mercedes, 2, 41012, Seville, Spain \\ \{mrequena1, ame, percy, eromero13\}@us.es
}

\begin{abstract}
Most seismic vulnerability analyses do not consider the Soil-Structure Interaction (SSI). However, it has been proved that SSI does not equally affect all types of structures and all types of soils. The analysis of the state of the art reveals that SSI especially affects the performance of mid/high-rise buildings under soft/inelastic soil conditions. This leads to overestimating the capacity of buildings and to obtaining unreliable results. This paper aims to assess the soil influence in the seismic vulnerability analysis of a reinforced concrete (RC) building. Three models of a real case study building have been determined (low-rise (real), mid-rise and high-rise). A pre-code 1970s case study building, located in Huelva, has been selected. This building shares typical constructive and structural characteristics with most RC buildings constructed during that period. The $3 D$ continuum model of the soil has been carried out to simulate its nonlinear behaviour. The most probable soil profile has been defined, observing a clayey soil. Therefore, the analyses have been performed under undrained conditions. Nonlinear static analyses have been carried out to determine the seismic capacity of the models through the finite element method (FEM). The damage has been assessed by means of the local procedure, defined in the European seismic code, and the global fragility procedure. The results have shown that the soil does not significantly influence the behaviour of low-rise buildings. However, in the case of mid-and high-rise buildings, the maximum capacity can be reduced by up to $10 \%$ and $30 \%$, respectively.
\end{abstract}

Keywords: Soil Structure Interaction, Seismic analysis, Reinforced concrete, Buildings, OpenSEEs. 


\section{INTRODUCTION}

Most seismic vulnerability analyses of buildings are carried out without considering the soil-structure interaction effects (SSI). Despite these notable effects, their consideration in seismic analysis remains unclear. In fact, SSI was assumed to be beneficial in past research [1]. This benefit emerges from the reduction of the internal forces and the drifts due to the soil's increasing flexibility. Hence, the vast majority of seismic vulnerability analyses consider models with a fixed-based configuration to obtain more conservative results. However, recent studies on the influence of SSI in the capacity assessment of buildings has proved that it does not positively affect all types of structures and all types of soils [2]. They have concluded that structures are expected to experience different levels of damage when the soil's influence is taken into account [3]. In fact, the Eurocode-8 Part-1 (EC8-1) [4] establishes that the SSI effects must be born in mind when structures: i) present significant second order $(p-\Delta)$ effects; ii) are slender; or, iii) are medium/high-rise buildings. Moreover, it was proved that SSI might affect aspects related to the seismic performance of buildings such as the ductility and the strength [5] or the energy dissipation [6]. Studies have even shown that the SSI can greatly worsen the performance of buildings due to asymmetrical designs [7]. This suggests that further research is needed.

The SSI effects can be taken into account by simulating the flexibility of the soil. To do so, several approaches have been proposed over time. Among others, the most common approaches used in the behaviour assessment of buildings are the Nonlinear Beam on Winkler method (NBWM) and the continuum modelling of soil (in 3D). The first approach is mainly based on simulating the nonlinear behaviour of the soil by adding inelastic springs [8]. These springs present different characteristics which are applied in certain directions. The NBWM can simulate the SSI effects very easily and simply. In this way analyses do not become very tedious [9]. However, this approach presents certain drawbacks: it does not consider the complete behaviour of the soil, the frictional surface between the soil and the foundation and the effects of deeper soil layers. Therefore, this method might not be applicable for all soil and structural characteristics.

The continuum modelling of soils can exhaustively capture the soil constitutive behaviour, obtaining more realistic results [2]. Moreover, this type of analyses has been gaining importance over the past decade due to the availability of new methods and the increase of computational capacity [10]. Some related studies showed that the foundation characteristics and the soil modulus (shear and bulk) are the parameters that most affect the seismic response of buildings [2]. Others proved that the SSI are significant when both the structure and the soil are simulated as inelastic [6]. These parameters cannot be considered in SSI assessment via the NBWM.

Owing to the lack of studies and guidance, this paper aims to analyse the soil's influence in the seismic vulnerability analysis of a reinforced concrete (RC) building. To do so, different models of a real case study building have been simulated (low-rise (real), mid-rise and highrise). The EC8-1 statement and past research have been proved. The 3D continuum modelling of the soil has been carried out to simulate its nonlinear behaviour. Furthermore, the characterisation of the most probable soil profile at the location has been done by considering different geotechnical studies. As a clayey soil has been observed, the analyses have been carried out under undrained conditions. Nonlinear static analyses have been performed to determine the seismic capacity of models by using the finite element method (FEM). The damage has been assessed by means of the local procedure established in Eurocode-8 Part-3 (EC8-3) [11] and the fragility procedure. 
The case study building is a 1970s primary school building located in Huelva (southwestern Spain), which is an earthquake-prone area. This building shares typical constructive and structural characteristics with most RC buildings of the area. What is more, these buildings were constructed prior to the applications of seismic codes.

The key contributions of this paper are: i) the analysis of the soil influence in the seismic vulnerability analysis of RC buildings considering different geometrical characteristics; ii) the characterisation for the 3D continuum modelling of the most probable soil profile in Huelva; iii) 3D FEM models in OpenSees to realistically reproduce the entire system's behaviour (soil+foundation+structure); iv) the analysis of the seismic damage by means of both local and global procedures.

\section{CASE STUDY}

\subsection{Building configuration}

The case study building selected is a primary school building located in Huelva. It has been defined as an index-building of the typology of RC buildings [12]. This typology represents $27 \%$ ( 75 buildings) of the total (279) of the primary school buildings constructed in the province. As they were built during the 1970s, they share constructive and structural characteristics with a major part of the area's RC buildings: insufficient longitudinal and transversal rebar ratio, wide beams, short columns, very slender RC columns sections and low-quality structural materials. Moreover, these buildings have not been designed according to seismic criteria since they were constructed prior to restrictive seismic codes.

The case study building is a two-story RC frame building (Figure 1). Although it is regular in height, it presents short columns on the ground floor. This is a typical constructive configuration that can be commonly found in most RC buildings of the 1970s. Short columns are created due to the elevation of the ground floor from the soil surface to avoid humidity and water problems. This ground-floor construction often leads to isolated footings (superficial or deep). In this case, the building was constructed with isolated footings of a depth of $0.80 \mathrm{~m}$. The structural characteristics of the building are listed in Table 1.
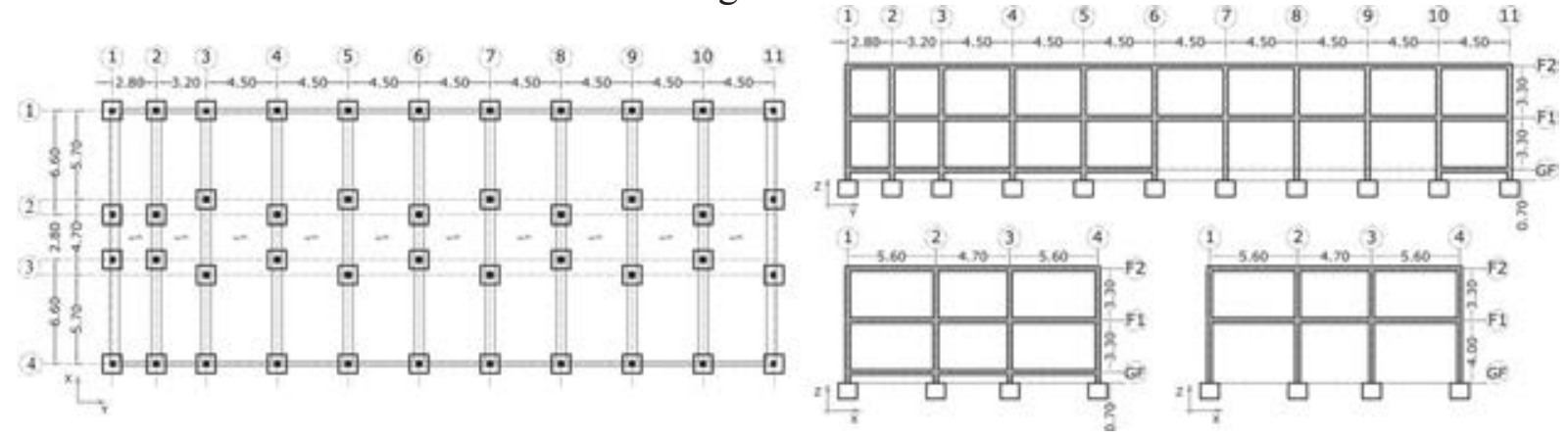

Figure 1: Case study building's configuration.

\begin{tabular}{lccc}
\hline Characteristic & Columns & Load beams & Tie beams \\
\hline Dimensions $(\mathrm{cm})$ & $30 \times 40$ & $60 \times 30$ & $30 \times 30$ \\
Cross-section $\left(\mathrm{cm}^{2}\right)$ & 1,200 & 1,800 & 900 \\
Longitudinal rebar $\left(\mathrm{cm}^{2}\right)$ & 1.572 & Top: 0.786 & Top: 0.786 \\
Transversal rebar $\left(\mathrm{cm}^{2}\right)$ & 0.196 & Bottom: 3.495 & Bottom: 0.786 \\
Spacing of stirrups $(\mathrm{cm})$ & 15 & 0.196 & 0.196 \\
\hline
\end{tabular}

Table 1. Case-study's structural elements geometrical characteristics. 


\subsection{Soil characterisation}

A characterisation of the soil under the building has been carried out to properly model its constitutive behaviour. The information has been compiled from 8 nearby geotechnical studies. These studies include information related to laboratory tests done with samples as well as in-situ geotechnical prospections. Based on the available information, an interpretation of the soil layering at the site has been performed. In this study, the most probable soil profile has been considered. To do so, the probability of each stratum according to its depth has been assessed. This determination has considered 17 boreholes. As shown in Figure 2a, four different geotechnical strata have been identified: tilled, grey clay, brown silt and clay loam. The laboratory tests have revealed a predominance of clay. Therefore, only the parameters to perform undrained analyses have been calculated.

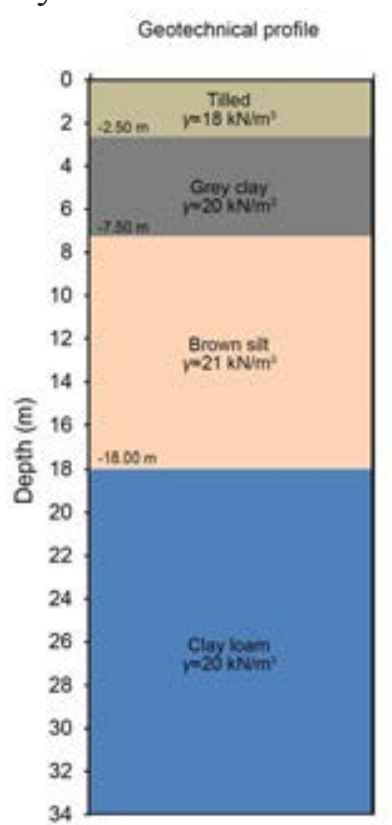

(a)

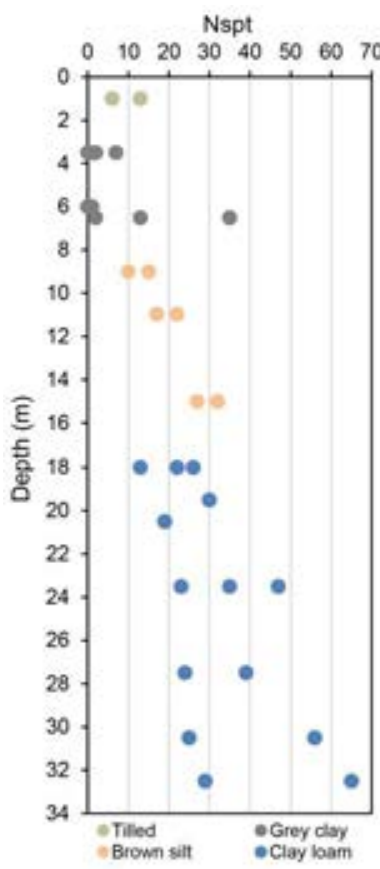

(b)

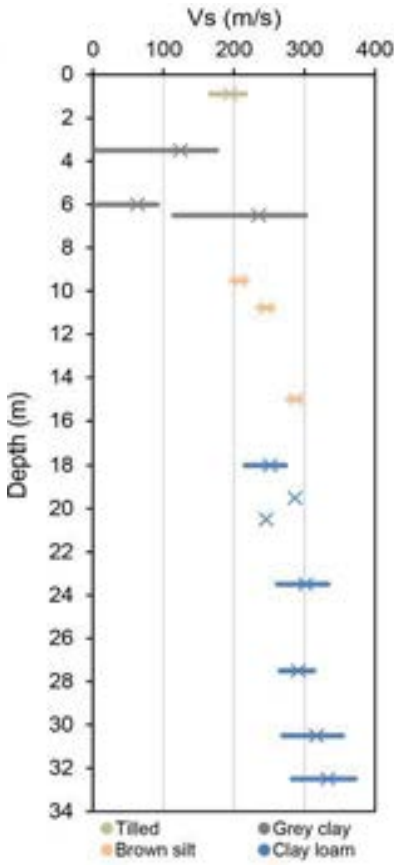

(c)

Figure 2: Soil characterization. (a) Soil profile (b) $N_{\text {spt }}$ and $V_{\mathrm{s}}$ (c) according to depth.

Among other in-situ tests, standard penetration tests (SPT) were executed to determine the

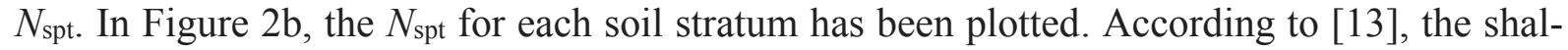
low layers can be classified as low-dense soils $\left(N_{\text {spt }} \approx 11-30\right)$ while the deepest layers are dense $\left(N_{\text {spt }} \approx 31-50\right)$.

The shear wave velocity $\left(V_{\mathrm{s}}\right)$ and the Poisson ration $(v)$ are required to numerically model the soil in 3D. In [14], several correlations were defined to obtain $V_{\mathrm{s}}$. However, in this work, only the Imai equation (Eq.(1)) has been used since it is widely accepted. In Figure $2 \mathrm{c}$, the $V_{\mathrm{s}}$ values for each soil layer have been defined according to $N_{\text {spt }}$ and depth. Since there are several values of $V_{\mathrm{s}}$ for each depth, the most probable value has been used to determine the parameters presented below.

$$
V_{\mathrm{s}}=91 N_{\mathrm{spt}}^{0.317}
$$

The soil behaviour is defined according to three parameters: shear $(G)$, elastic $(E)$ and bulk $(B)$ modulus and the unit weight $(\gamma)$. The moduli have been calculated according to certain widely known geotechnical correlations (Eq.(2)(3)(4)). $G, E$ and $B$ have been plotted in Figure 3 for each soil stratum. The soil constitutive behaviour has been plotted considering the 
medium values of each modulus. As can be observed, the shallow layers are weaker than the deepest ones, which relates to $N_{\text {spt. }}$. The soil stiffness increases at around $5 \mathrm{~m}$ depth. The clay loam's modulus rises slightly with depth. In order to take the variability of the modulus into account, four soil layers have been defined following the procedure established in Section 4.2.

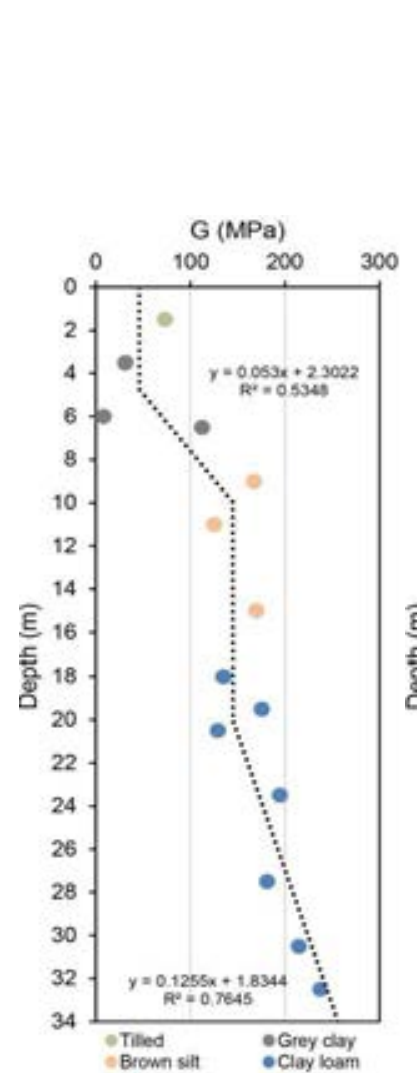

(a)

$$
\begin{gathered}
G=\gamma V_{\mathrm{s}}^{2} \\
E=2 G(1+v) \\
B=E / 3(1-2 v)
\end{gathered}
$$

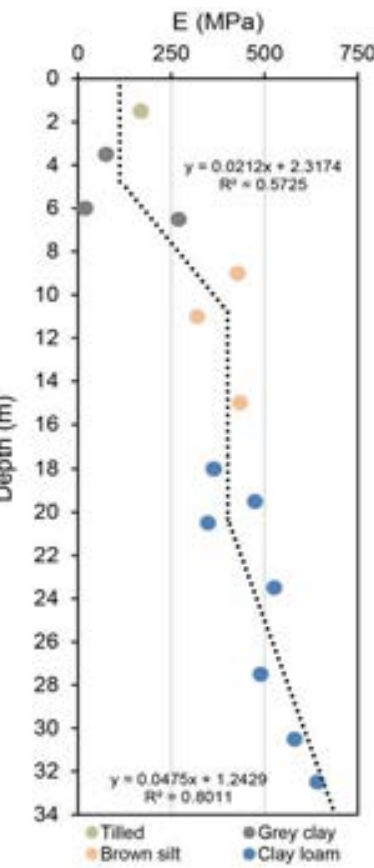

(b)

Figure 3: $G(\mathrm{a}), E(\mathrm{~b})$ and $B(\mathrm{c})$ values obtained from correlations according to geotechnical prospections.

\section{NONLINEAR STATIC ANALYSES}

\subsection{Models defined}

The state of the art has revealed that SSI must be considered in the seismic analyses of mid- and high-rise buildings. Therefore, in order to better understand their influence, different configurations of the case study building have been determined by varying its height. As shown in Figure 4, three models have been defined: low-rise (real) (M1), mid-rise (M2) and high-rise (M3). The total mass and height of each model have been listed in Table 2. Fixedbase and solid models have been identified with "F" and "S", respectively. The nodes at the base of the F-models have been fixed in the 6 degrees of freedom (DOF): X, Y, Z, Rx, $\mathrm{R}_{\mathrm{y}}$ and $\mathrm{R}_{\mathrm{z}}$. The modelling of the soil is presented in Section 4.2. It has also been checked that the foundations' dimensions are valid for the soil with each model's configuration. 


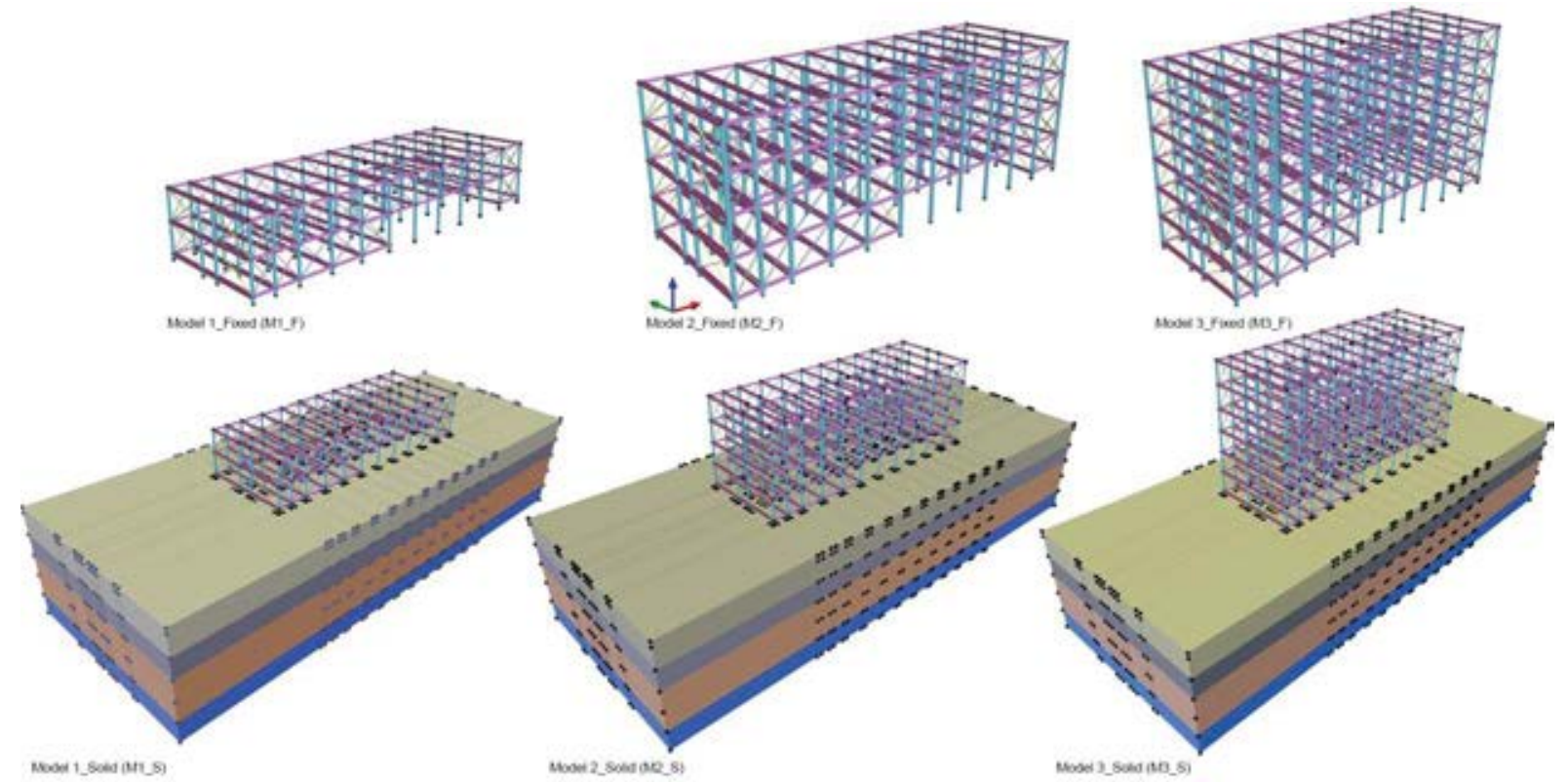

Figure 4: Models' configuration.

\begin{tabular}{cccc}
\hline Model & $\mathrm{N}^{\mathrm{o}}$ of floors & Total mass (ton) & Total height (m) \\
M1 & 2 & 1,058 & 7.30 \\
M2 & 4 & 1,952 & 13.90 \\
M3 & 6 & 2,846 & 20.50 \\
\hline
\end{tabular}

Table 2. Number of floors, total mass and height of the models analysed.

\subsection{Analysis procedure}

Nonlinear static analyses have been carried out to determine the capacity of the models by using the FEM OpenSees software [15]. Since the models are very large, the analyses have been done using the parallel option available in OpenSees by defying partitions. The outputs have been handled in PYTHON [16]. A load-control and displacement-control integrator have been used to perform the gravity and the pushover analyses, respectively. Only the modal load pattern results have been considered since this has been the most restrictive. Modal analyses have been carried out to define the load pattern. The -genBandArpack solver has been used due to the numerous constraints. As models have worked in Mode 1 and 2, torsional effects can be neglected.

\subsection{Damage determination}

The N2-method has been used to determine the single-degree-of-freedom (SDOF) idealised bilinear curves and the target displacement. Its extended version has also been used, which takes the infills' effects into account. A 0.1g PGA for Huelva has been used according to the Spanish updated seismic action values [17]. The response spectrum has been constructed using the EC8-1 procedure.

Two approaches have been considered to determine the damage: the local and the global. The first one has borne in mind the demand/capacity ratio (DCR) established in EC8-3 and the local damage of RC structural elements. Three damage states have been determined: damage limitation (DL), significant damage (SD) and near collapse (NC). The NC is calculated considering the ultimate chord rotation $\left(\theta_{\mathrm{um}}\right)$. The SD is determined as $3 / 4 \mathrm{of} \theta_{\mathrm{um}}$. The DL is worked out by means of the yielding chord rotation $\left(\theta_{\mathrm{y}}\right)$. The formulae of each parameter are 
established in the EC8-3. Each damage state has been calculated when the demand chord of one column reaches the capacity values of $\theta_{\mathrm{um}}, \theta_{\mathrm{um}}$ and $\theta_{\mathrm{y}}$.

The second approach is based on the fragility curves assessment. These curves provide the probability of reaching or exceeding a certain damage state $\left(d_{\mathrm{s}}\right)$, given a certain spectral displacement $\left(S_{\mathrm{d}}\right)$. They are determined by the well-known lognormal cumulative distribution (Eq.(5)), where: $\beta_{\mathrm{ds}}$ is the dispersion at $d_{\mathrm{s}}$ and $S_{\mathrm{d}, \mathrm{ds}}$ is the median value of the spectral displacement at which a building reaches the $d_{\mathrm{s}}$ threshold.

$$
P\left[d_{\mathrm{s}} \mid S_{\mathrm{d}}\right]=\Phi\left[\left(1 / \beta_{\mathrm{ds}}\right) \ln \left(S_{\mathrm{d}} / S_{(\mathrm{d}, \mathrm{ds})}\right)\right]
$$

Both $\beta$ ds and $S_{\mathrm{d} \text {,ds }}$ are statistical parameters that take into account different uncertainties. They should therefore be determined according to the models analysed. However, in this case they have not been studied since further research should be carried out considering many models and including the SSI effects. However, an exhaustive work carried out in [18] has been used to define these parameters. The authors performed the fragility assessment of typical Spanish RC buildings and determined the fragility parameters for low-, mid- and high-rise RC buildings. The values of $\beta_{\mathrm{ds}}$ for each building class are listed in Table 5. The values of $S_{\mathrm{d}, \mathrm{ds}}$ have been determined for each of the models analysed and following the provisions established in [18], listed in Table 4. This procedure considers the parameters that characterise the idealised SDOF system curves: $D_{\mathrm{y}}$ and $D_{\mathrm{u}}$, yielding and ultimate displacement.

\begin{tabular}{ccccc}
\hline Damage state/Class & Slight $\left(\beta_{1}\right)$ & Moderate $\left(\beta_{2}\right)$ & Severe $\left(\beta_{3}\right)$ & Complete $\left(\beta_{4}\right)$ \\
Low-rise & 0.28 & 0.37 & 0.82 & 0.83 \\
Mid-rise & 0.28 & 0.36 & 0.50 & 0.61 \\
High-rise & 0.28 & 0.29 & 0.34 & 0.45 \\
\hline
\end{tabular}

Table 3. $\beta_{\mathrm{ds}}$ for each RC building class.

\begin{tabular}{cccc}
\hline Slight $\left(S_{d 1}\right)$ & Moderate $\left(S_{d 2}\right)$ & Severe $\left(S_{d 3}\right)$ & Complete $\left(S_{d 4}\right)$ \\
$0.7 D_{\mathrm{y}}$ & $D_{\mathrm{y}}$ & $D_{\mathrm{y}}+0.25\left(D_{\mathrm{u}}-D_{\mathrm{y}}\right)$ & $D_{\mathrm{u}}$ \\
\hline
\end{tabular}

Table 4. $S_{\mathrm{d}, \mathrm{ds}}$ determination for each damage state threshold.

\section{NUMERICAL MODELLING}

The different models considered in this study have been modelled with the STKO software [19], a Graphical User Interface (GUI) for OpenSees.

\subsection{Superstructure}

The nonlinear behaviour of the RC elements has been simulated though the distributed plasticity approach. This can automatically compute deformations and curvatures, reducing the modelling time. The RC beams and columns have been discretised into different fibres with the fibre section aggregator. In order to take $p$-delta $(p-\Delta)$ effects into account, forcebeams elements have been applied to the RC frames. "Concrete 01 " has been considered to simulate concrete. The concrete's core has been defined by increasing its strength and strain according to [20]. "Stee102" has been used to model steel. In this case, the smooth rebars have been considered by decreasing the steel elastic modulus as in [21]. The effects of infills have been taken into account by means of the two-diagonal truss approach defined in [22]. Due to the rigidity of the concrete slabs, rigid diaphragm interactions have been applied to the nodes of each floor. Masses have been applied to each structural member considering the gravitational loads and the self-weights. Gravitational loads have also been applied to each structural element bearing in mind: dead (self- weight and the weight of constructive elements) and live 
loads. The characteristics of the structural materials considered in this study are listed in Table 5 .

\begin{tabular}{llllll}
\hline Concrete & & Steel & \multicolumn{3}{l}{ Infills } \\
\hline$f_{\mathrm{c}}(\mathrm{MPa})$ & 28 & $f_{\mathrm{y}}(\mathrm{MPa})$ & 370 & $G_{\mathrm{w}}(\mathrm{GPa})$ & 1240 \\
$f_{\mathrm{cu}}(\mathrm{MPa})$ & 4 & $E_{\mathrm{s}}(\mathrm{GPa})$ & 310 & $\alpha$ & 0.05 \\
$\varepsilon_{\mathrm{c}}(\%)$ & 0.002 & & & $\tau_{\mathrm{cr}}(\mathrm{MPa})$ & 280 \\
$\varepsilon_{\mathrm{cu}}(\%)$ & 0.04 & & & $E_{\mathrm{w}}(\mathrm{GPa})$ & 4092 \\
\hline
\end{tabular}

Table 5. Values of the structural materials' parameters.

Where: concrete compressive $\left(f_{\mathrm{c}}\right)$ and crushing strength $\left(f_{\mathrm{cu}}\right)$; concrete strain at maximum $\left(\varepsilon_{\mathrm{c}}\right)$ and ultimate strength $\left(\varepsilon_{\mathrm{cu}}\right)$; steel yielding strength $\left(f_{\mathrm{y}}\right)$; steel modulus of elasticity $\left(E_{\mathrm{s}}\right)$; infills shear modulus $\left(G_{\mathrm{w}}\right)$; postcapping degrading branch coefficient $(\alpha)$; shear cracking stress $\left(\tau_{\mathrm{cr}}\right)$; masonry elasticity modulus $\left(E_{\mathrm{w}}\right)$.

\subsection{Continuum modelling of the soil}

The underlying soil of the building has been modelled with a mesh of $125 \times 40 \times 21 \mathrm{~m}$ (X, Y and $\mathrm{Z}$ directions). The mesh has been defined according to the $V_{\mathrm{s}}$ and to the frequency $(\omega)$ of the models. "SSPbrick" brick elements have been applied to the solid elements to capture the soil small deformation (Figure 5). The mesh is characterised by 51,954 nodes and 120,040 brick elements. The lateral boundaries have been fixed in the corresponding direction and the base in all directions.

According to the different test results (Section 2.2), the soil beneath the building is clayey. Therefore, the analyses have been performed under undrained conditions since this is the most restrictive. Hence, the soil constitutive behaviour has been simulated by means of the "PressureIndependMultiYield" (PIMY) material. This has been implemented in OpenSees to model elasto-plastic undrained clay-type soils, which are independent from pressure. The soil's failure criterion is based on Von Mises' multi-surface plasticity theory (Figure 5) determined in [23]. "EqDOF" has been applied to the interaction between the soil's and the foundation's surfaces. Four soil layers have been defined according to the characterisation performed in Section 2.2, which can be observed in Figure 4.
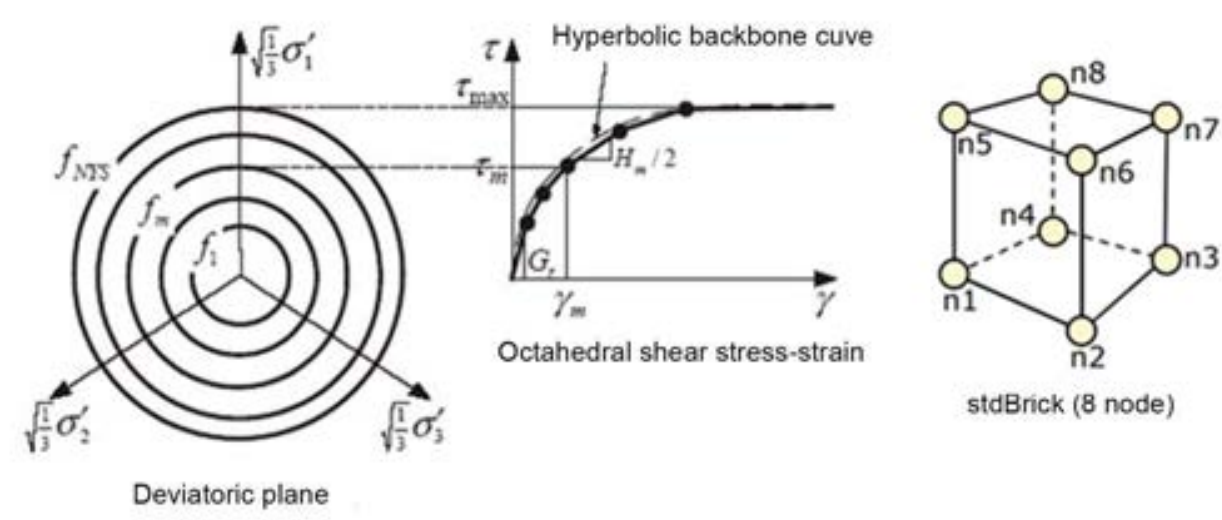

Figure 5: "PressureIndependMultiYield" soil material's failure criterion.

\section{RESULTS AND ANALYSIS}

The results obtained from the analyses appear in this section. In Figure 6, the deformed shape of each model after the application of the gravity loads is shown. As can be observed, the settlement of the structure is higher when the height increases. The displacement in the $\mathrm{Z}$ 
direction of the control node (in the rooftop) increases $220 \%$ and $323 \%$ when adding 2 floors (M2) and 4 floors (M3), respectively. Therefore, this increase is not linear.
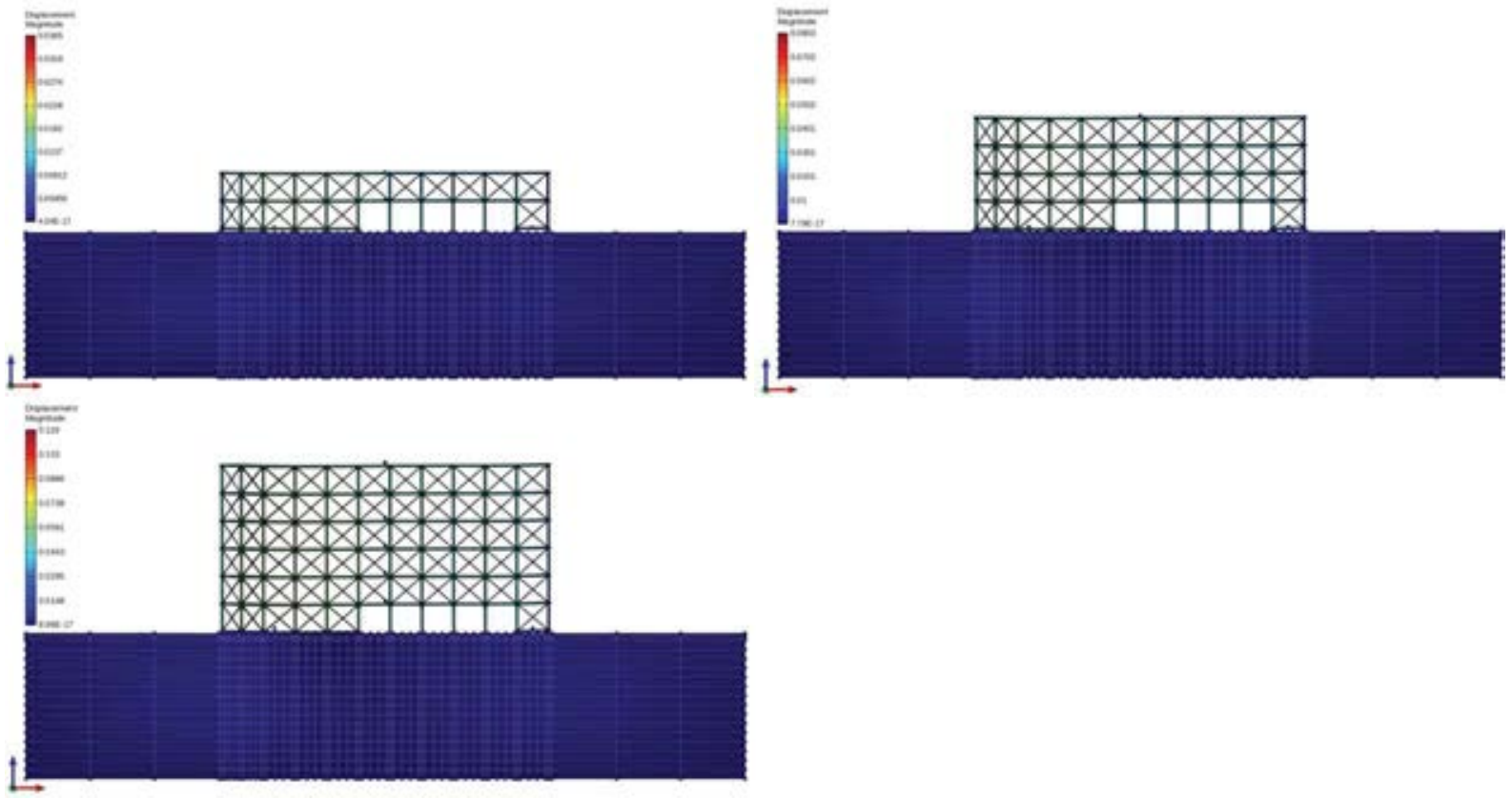

Figure 6: Deformed shape of models analysed after the application of gravity loads.

In Figure 7, the SDOF capacity curves for each of the models have been plotted. Also, the damage states (Section 3.3) and the target displacements (demand) have been determined. In order to compare the results, the multi-degree-of-freedom (MDOF) curves have been normalised by dividing the base shear $\left(V_{\mathrm{b}}\right)$ by the weight $(W)$ and the displacement $(d)$ by the total height $\left(H_{\mathrm{t}}\right)$.
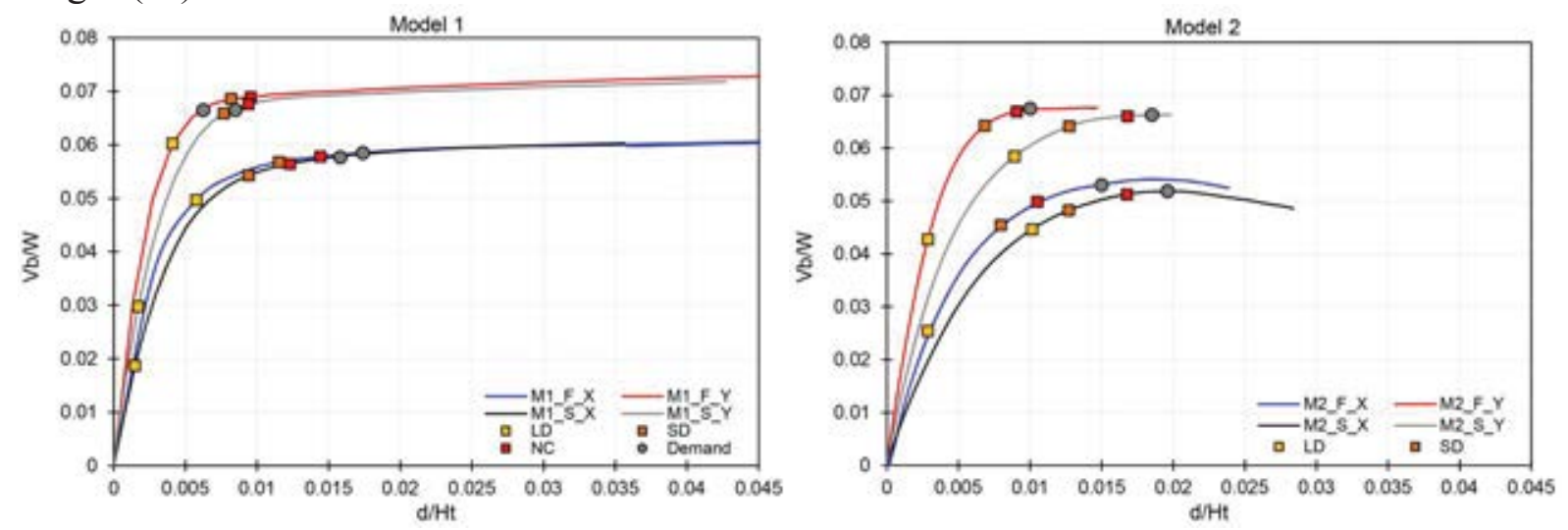


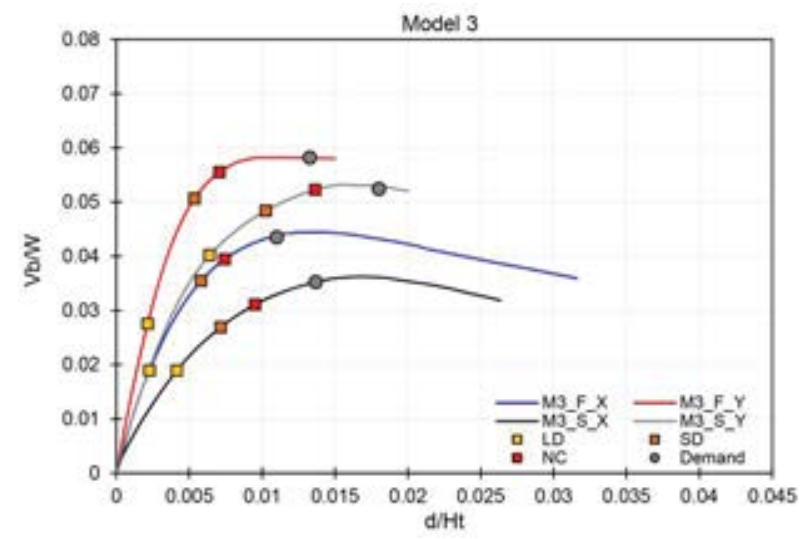

Figure 7: SDOF normalised capacity curves for each of the models assessed.

It can be observed that the higher the structures' height, the higher the soil effects. In the case of the low-rise model (M1), the SSI just decreases the initial stiffness of the systems. In the $\mathrm{X}$ direction, the difference between the demand and the $\mathrm{NC}$ displacement is higher for the $\mathrm{S}$ models. In the Y direction, for the F model, the demand is located between the LD and the SD. However, when considering the SSI, the demand is after the SD; therefore, it will not comply with the EC8 requirements like in the X direction. Mid-rise buildings are more affected by the SSI than low-rise buildings due to the considerable modification of the initial stiffness. The maximum capacity has been reduced by around $10 \%$. In the $\mathrm{Y}$ direction, the demand displacement is considerably higher for the $\mathrm{S}$ model. High-rise models are the most affected by the SSI, the maximum capacity being reduced by up to $30 \%$. In terms of damage, the models behave worse due to the failure of columns located in the irregularity of the ground floor.

In Figure 8, the fragility curves for each of the models analysed are plotted considering the demand displacement. It can be noted that the fragility curves for the models with SSI are worse than the F-model's curves. Therefore, the probability of reaching higher damage increases in models that bear the soil influence in mind. This probability also increases with the height. As can be seen, the S-model's fragility curves are worse than the F-model's curves when the height increases. This results in the high-rise models being the most affected. Moreover, the fragility curves of high-rise buildings are worse than the rest due to the statistical parameters' values.
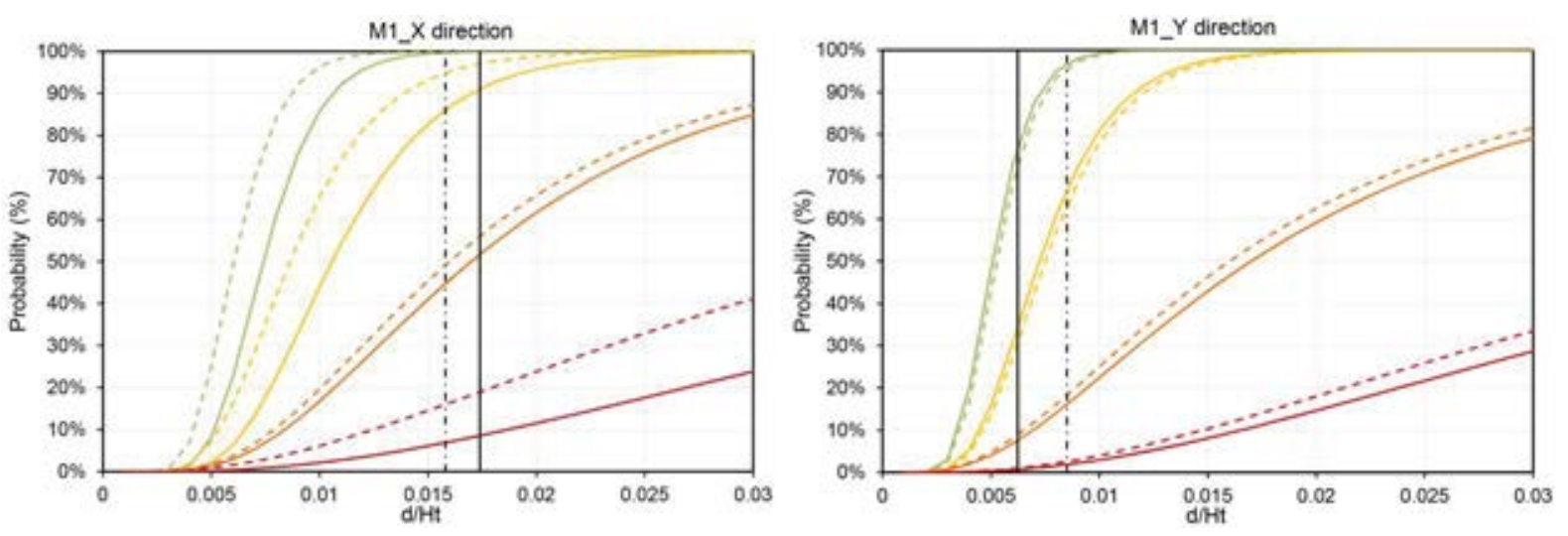

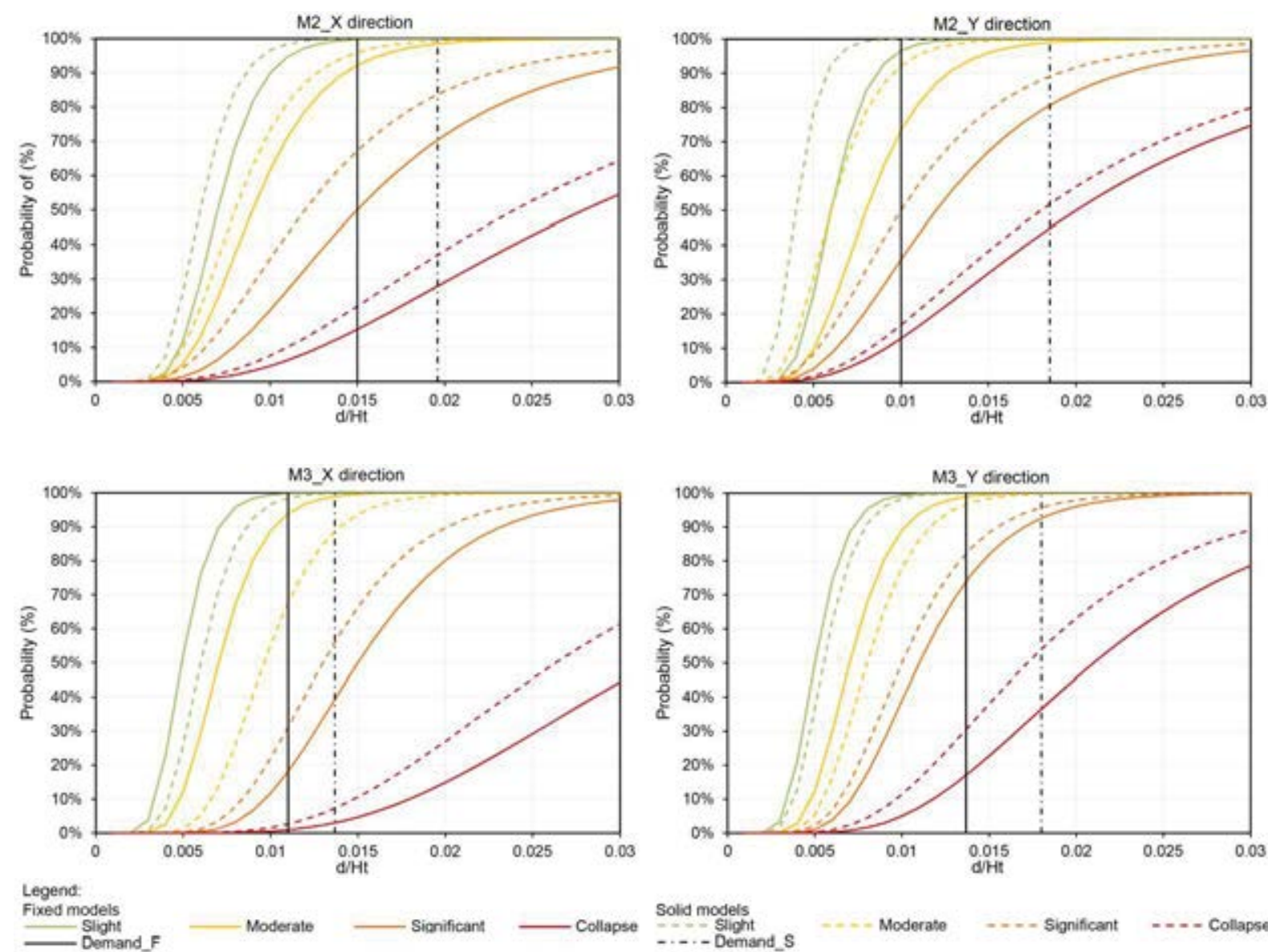

Figure 8: fragility curves considering fixed-based and solid models and low-, mid- and high-rise models.

\section{CONCLUSIONS}

This paper aims to analyse the SSI in the seismic vulnerability analysis of RC buildings. The state of the art has revealed that SSI must be considered in the seismic analyses of midand high-rise buildings. Therefore, different configurations of a case study RC building have been defined by varying the height: low- (real), mid- and high-rise. The characterisation of the location's soil profile has been carried out. This characterisation has revealed that the soil is clayey.

Nonlinear static analyses have been performed to assess the models' capacity. The seismic damage has been determined by means of the European seismic code (local damage of elements) and the fragility procedures (global damage). 3D nonlinear models considering the soil as a continuum have been modelled using the FEM to simulate the soil nonlinear behaviour.

The results have shown that the soil does not significantly influence the behaviour of lowrise buildings. However, in the case of mid- and high-rise buildings, the maximum capacity can be reduced by up to $10 \%$ and 30\%, respectively. Moreover, according to the local damage assessment, structural elements might collapse due to considering the soil, even for low-rise buildings.

In the light of the fragility assessment results, it can be concluded that the probability of reaching higher seismic damage increases when considering the SSI. Moreover, this probability increases with the height.

This work has considered the most probable soil profile that can be found in the area. However, further research should be carried out in order to consider several soil profiles since softer layers could worsen the building's seismic capacity. This research has considered statis- 
tical parameters from other works in the fragility assessment. Yet, further research should be assessed to properly determine these values according to the models' characteristics and the type of soil. This research has not considered the element contact between the soil and the foundation's surfaces, which can capture the soil behaviour better, leading to more accurate results.

\section{REFERENCES}

[1] Kwag, S., Ju, B.S., \& Jung, W., Beneficial and Detrimental Effects of Soil-Structure Interaction on Probabilistic Seismic Hazard and Risk of Nuclear Power Plant. Advances in Civil Engineering, 2018, 2018.Epub ahead of print 2018. DOI: 10.1155/2018/2698319.

[2] Anand, V., \& Satish Kumar, S.R., Seismic Soil-structure Interaction: A State-of-theArt Review. Structures, 16, pp. 317-326, 2018.

[3] Rajeev, P., \& Tesfamariam, S., Seismic fragilities of non-ductile reinforced concrete frames with consideration of soil structure interaction. Soil Dynamics and Earthquake Engineering, 40, pp. 78-86, 2012.

[4] European Union., Eurocode 8: Design of structures for earthquake resistance. Part 1: General rules, seismic actions and rules for buildings. Belgium, 2004.

[5] Miranda, E., \& Bertero, V. V., Evaluation of strength reduction factors for earthquake-resistant design. Earthquake Spectra, 10(2), pp. 357-379, 1994.

[6] Karapetrou, S.T., Fotopoulou, S.D., \& Pitilakis, K.D., Seismic vulnerability assessment of high-rise non-ductile RC buildings considering soil-structure interaction effects. Soil Dynamics and Earthquake Engineering, 73, pp. 42-57, 2015.

[7] Badry, P., \& Satyam, N., Seismic soil structure interaction analysis for asymmetrical buildings supported on piled raft for the 2015 Nepal earthquake2016.Epub ahead of print 2016. DOI: 10.1016/j.jseaes.2016.03.014.

[8] Boulanger, R.W., Curras, C.J., Kutter, B.L., Wilson, D.W., \& Abghari, A., Seismic Soil-Pile-Structure Interaction Experiments and Analyses. Journal of Geotechnical and Geoenvironmental Engineering, 125(9), pp. 750-759, 1999.

[9] Harden, C.W., \& Hutchinson, T.C., Beam-on-Nonlinear-Winkler-Foundation Modeling of Shallow, Rocking-Dominated Footings. Earthquake Spectra, 25(2), pp. 277-300, 2009.

[10] Cayci, B.T., Inel, M., \& Ozer, E., Effect of Soil-Structure Interaction on Seismic Behavior of Mid-and Low-Rise Buildings. International Journal of Geomechanics, 21(3), pp. 04021009, 2021.

[11] European Union., Eurocode-8: Design of structures for earthquake resistance. Part 3: Assessment and retrofitting of buildings. Belgium, 2005.

[12] Morales Esteban, A. et al., Schools: seismicity and retrofitting (PERSISTAH project). Universidad de Sevilla, 2020.

[13] Spanish Ministry of Public Works [Ministerio de Fomento de España]., Spanish Technical Code of Buildings [Código Técnico de la Edificación (CTE)]. Spain, 2006. 
[14] Naik, S.P., Patra, N.R., \& Malik, J.N., Spatial Distribution of Shear Wave Velocity for Late Quaternary Alluvial Soil of Kanpur City, Northern India. Geotechnical and Geological Engineering, 32(1), pp. 131-149, 2014.

[15] McKenna, F., Fenves, G.L., \& Scott, M.H., OpenSees: Open system for earthquake engineering simulation 2000 .

[16] Python Software Foundation., Python2021.

[17] Spanish Ministry of Public Works [Ministerio de Fomento de España]., Update of the seismic hazard maps [Actualización de mapas de peligrosidad sísmica de España]. Spain, 2012.

[18] Barbat, A.H., Pujades, L.G., \& Lantada, N., Seismic damage evaluation in urban areas using the capacity spectrum method: Application to Barcelona. Soil Dynamics and Earthquake Engineering, 28(10-11), pp. 851-865, 2008.

[19] Petracca, M., Candeloro, F., \& Camata, G., I"STKO user manual|". ASDEA Software Technology. Pescara Italy, 2017.

[20] Mander, J.B., Priestley, M.J.N., \& Park, R., Theoretical Stress-Strain Model for Confined Concrete. Journal of Structural Engineering, 114(8), pp. 1804-1826, 1988.

[21] Couto, R., Requena-García-Cruz, M., Bento, R., \& Morales-Esteban, A., Seismic capacity and vulnerability assessment considering ageing effects. Case study: Three local Portuguese RC buildings. Bulletin of Earthquake Engineering2020.Epub ahead of print 2020. DOI: 10.1007/s10518-020-00955-4.

[22] Celarec, D., Ricci, P., \& Dolšek, M., The sensitivity of seismic response parameters to the uncertain modelling variables of masonry-infilled reinforced concrete frames. Engineering Structures, 35, pp. 165-177, 2012.

[23] Mazzoni, S., McKenna, F., Scott, M.H., \& Fenves, G.L., OpenSees command language manual. 2006. 